\title{
Exploration of the New-type Urbanization Paths for Yuxi Three-lake Ecological Urban Agglomeration
}

\author{
Yun Bai ${ }^{1}$, Chongke $\mathrm{Li}^{2}$, Shan Qin ${ }^{3}$, Nihong Xie ${ }^{4}$ \\ 1,2,3,4 Yuxi Normal University, Yuxi Yunnan, 650031, China
}

Keywords: Three-lake ecological urban agglomeration, New-type urbanization, Paths.

\begin{abstract}
Yuxi owns three advantaged plateau lakes, the proposal of building Yuxi three-lakes ecological urban agglomeration for the development of the three-lake drainage basin shall follow the principle of protection first, moderate exploitation and concentrated development, and we shall prudently chose the regions with development conditions for urbanization. Quicken the pace of eastward urban expansion while strengthening the core status of Hongta District, and cultivate the development pole in Yuxi three-lake region; settle the contradictions between urbanization development and lake resources protection; with the protection and development of lake resources as power, develop the industrial cluster with ecology first and creativity as the core to realize the interactive development between regional urban and rural areas.
\end{abstract}

\section{Introduction}

Yuxi owns three plateau lakes and the water resources are very abundant. The three plateau fault-depression lakes are Fuxian Lake in Chengjiang County, Xingyun Lake in Jiangchuan District and Qilu Lake in Tonghai County. The area of Fuxian Lake is $212 \mathrm{~km}^{2}$, the altitude of water level is $1721 \mathrm{~m}$, the longest depth is $155 \mathrm{~m}$, the mean depth is $87 \mathrm{~m}$, and it is the second deepest lake in China with total water storage of 18.5 billion $\mathrm{m} 3$; the area of Xingyun Lake is $34.7 \mathrm{~km}^{2}$, the mean depth is $7 \mathrm{~m}$, the water storage is 189 million $\mathrm{m} 3$, and the altitude of normal pool level is $1722.15 \mathrm{~m}$; the area of Qilu Lake is $37.26 \mathrm{~km}^{2}$, the mean depth is $4.5 \mathrm{~m}$, the water storage is 168 million $\mathrm{m} 3$, and the altitude of normal pool level is $1797.25 \mathrm{~m}$. The exploration and analysis of the new-type urbanization paths for Yuxi three-lake ecological urban agglomeration is a proposition on the mutualism of new-type urbanization and plateau lakes.

\section{The background of new-type urbanization of Yuxi three-lake ecological urban agglomeration}

New-type urbanization has become a focused issue after the 18th CPC National Congress, which has been elevated to a strategic level. For a long time, Chinese urbanization development has laid particular stress on the big cities, mega-cities and super mega-cities in coastal developed areas and ignored the development of small cities and towns in middle part. Moreover, the urbanization progress in different provinces is different. Some cities are developed rapidly. For example, the urbanization rates of Beijing, Shanghai, Tianjin and some other big cities have been more than $80 \%$, but the urbanization rates of some cities are still low. In 2010, the urbanization rate in Yunnan minority concentrated areas was about $35.2 \%$, which was during the acceleration period and critical period of urbanization and at the lower level of urbanization. In 2015, the new-type urbanization rate was $42.9 \%$, which was antepenultimate in whole country. The regions with lower urbanization rates than Yunnan were only Xizang and Guizhou.

It is proposed in the Outline of the $12^{\text {th }}$ Five-Year Plan for National Economy and Social Development of Yuxi City (2014-2020) that we shall insist on paying equal attention to overall coordination, urban-rural integration, material civilization and spiritual civilization to promote the people-centered new-type urbanization construction in order to build a regional central city in Yunnan Province. Break the constraints of administrative division, overall plan the urban 
agglomeration with simultaneous development of the four modernizations, improve the level of urban development, urban management and the integration of industry and city, adhere to industry re-feeding agriculture and city supporting countryside, improve the integrative development system and mechanism to promote the synchronous development of counties and beautiful villages and complete the building of an ecological, livable, civil, happy and charming city. Insist on placing the ecological civilization construction in a prominent strategic position, stick to saving and protection priority, optimize the development pattern of national land space, overall promote the saving utilization of resources, improve the environmental quality, and promote green development, cyclic development and low carbon development to build a beautiful Yuxi, and strive to be the vanguard of ecological civilization construction in the province to build Yuxi to be an ecological, well-off and livable city with harmonious coexisting development of human and nature.

\section{The current situation of new-type urbanization of Yuxi three-lake ecological urban agglomeration}

In 2016, Yuxi speeded up the urbanization construction and completed the reform of 15 towns and townships and the administrative division adjustment of 33 sub-districts, implemented 42 small key city-level towns; the urban built-up area above county-level was $245 \mathrm{~km}^{2}$, the urbanization rate of permanent resident population was 43.9\%, and Yuxi was listed as a comprehensive pilot city with new-type urbanization in China. Strengthen the construction of central city, adjust the planning of Yuzhen Mount area, start the construction of the science and education innovation town, and speed up the construction of Ten Projects, such as high-speed rail new town, city planning library, the beautifying, virescence and brightening of urban road network. Start the reconstruction of old city and ecological remediation in the five old street areas, promote the construction of 290 sponge city projects, 15 comprehensive underground pipe galleries, 29 municipal roads and phase III of Yuxi River with all strength, complete the reconstruction and expansion of Honglong Road and the construction of railway station square and the surrounding road network, increase $53 \mathrm{~km}$ of new urban gas pipeline, and popularize it for 15000 resident users. Speed up the construction and development of counties and key towns, improve the quality and expand the capacity of the 2 demonstration counties: Chengjiang and E'shan, overall plan to promote the construction of the sponge counties, sponge towns, sponge villages, and complete the construction of Cambrian town and other 17 characteristic towns. Boost the integration of industry and city, make great efforts to the pilot of National Demonstration Area with Integration of Industry and City in High-tech Zone, scientifically distribute the industries in the park, gather the industries with the city, develop the city with industries, link up industries with the city, and integrate the development to drive population agglomeration and promote the floating rural population to be citizens. Chengjiang County governs 2 sub-streets, 4 towns, 40 administrative villages and communities, 380 villager (resident) groups and 322 natural villages. It is located in Yunnan central urban economic circle, three-lake ecological urban agglomeration, the ecological construction and comprehensive experimental area of tourism reform and development of Fuxian Lake and Xingyun Lake, and the core area of Kunyang-Yuxi tourism cultural industry economic belt. The urbanization rate in 2016 was 48.69\%. Jiangchuan District governs 1 sub-district, 4 towns and 2 townships. The urbanization rate is $45.1 \%$. It focus on the expansion of Jiangchuan central downtown to west of urban area and Longquan Industrial Park, and strengthens the ecological environment construction with the conservation governance of Fuxian Lake and Xingyun Lake as focus to build a modern, ecological, livable and new city with ancient Yunnan culture and lakes and mountains as characteristics. Tonghai County is a populated place of the Mongol nationality in Yunnan Province, which is located on the lacustrine plain beside of Qilu Lake with area of $721 \mathrm{~km}^{2}$ and 234000 residents. Its population density is highest in Yunnan Province, and the urbanization rate is $48.4 \%$. 


\section{Exploration of the new-type urbanization paths for Yuxi three-lake ecological urban agglomeration}

Two major relationships needing to be handled: (1) Understand the relationship between the protection of the three plateau lakes and the construction of ecological urban agglomeration. The first is the challenge from the water resource pollution in the plateau lakes, which causes the eutrophication that not only influences the industrial and agricultural production and living water for urban residents in the lake drainage basin, but also affects the ecological system of the lakes severely and endangers the survival of endemic species in Yunnan, such as schizothorax taliensis to cause the evolution in reverse of lake ecotope. The second is the change of the plateau lake ecosystem. The shortage of lake water resources will cause the decline of water level, water qualitative change, the lake surface narrowing and even drying, and the gradual loss of species diversity and functional diversity of the creatures in the lakes under the influence of human economical production. The inning of Qilu Lake of Tonghai County reduces the regulating and storing functions of the lake to cause the water area to be reduced sharply and influence the ecotope. (2) Industrial adjustment can drive regional development and be harmonious with the resources of the three plateau lakes. The three-lake ecological urban agglomeration is an area with most obvious interaction between the lake ecosystem and Yuxi urban ecosystem and most sensitive to human activities. The industrial development in YUxi three-lake ecological urban agglomeration area and the change of economic growth mode, such as the expansion of construction land, tourism development and agricultural production, will directly affect the structure function and ecology health of the lake ecosystem. The water resources in the lakes are the important inherent driving forces and constraints for the change of regional industrial structure, so we shall meet the demands of regional economic and social development in Yuxi, protect the lake ecosystem scientifically, and rationally develop and utilize the resources of the plateau lakes. Besides strengthening the research on the scientific issues of the lakes, we must select the industries and control the industry distribution reasonably and control the development of regions affecting the lake ecology greatly so as to gradually realize the coordinated development between economy and environment.

Urbanization power: the protection and development of the lake ecosystem is a key. (1) The sustainability idea of focusing on the protection of ecological lakes is the guarantee for a healthy lake ecosystem, which lies in the scientific planning firstly. Before the industrial distribution, we shall make a health evaluation of the lake ecosystem and take this as the guide and basis for confirming the industry selection and development scale in this region. A health evaluation system shall contain two aspects: the self-maintenance and updated ability of the lake ecosystem and the ability that the lake ecosystem meets the reasonable requirements of human society, and the main contents are: whether the ecosystem structure is healthy and complete; whether it has the ability of self-construction, self-repair, self-regulation and maintaining its own dynamic equilibrium; whether it can bear the human construction and development activities; the influence of the health and relative stability of ecosystem on the human survival and development. (2) Graded development mode. We divide the planning land in the region into three types according to the different influence on the lake ecology: the ecologically sensitive region of plateau lake, the ecologically direct influence region of plateau lake, and the ecologically indirect influence region of plateau lake. The ecologically sensitive region of plateau lake is the water source area of the lake and the upstream area of man-made lake and river system, which shall be controlled and protected to avoid exploitation and construction; the ecologically direct influence region of plateau lake is the hill, grassland, forest land and other areas around the lake and directly influencing the ecology, which can be developed protectively but avoid ecological influence to the greatest extent; the ecologically indirect influence region of plateau lake is the area far away from the lake but indirectly influencing the lake ecology by river network, underground water network and other systems, which can be combined organically through the sponge city project. (3) Guarantee the healthy operation of the lake ecosystem with persistent early warning mechanism. Develop it with long matching, feed back the health condition of the ecosystem, and establish the emergency mechanism to minimize the negative effects. Following three systems 
shall be established for the early warning mechanism for the health of the lake ecosystem: the health assessment and monitoring system of lake ecosystem, the general management operating system of lake ecosystem and the emergency management operating system of lake ecosystem.

Urbanization paths: with the industry development idea of Creation Surge and Ecology First and based on the capacity and bearing capacity of resources and environment, promote the upgrading of the industrial structure in the lake area, strengthen the protective development and comprehensive utilization of ecological species in the wetland, and focus on development of the cold chain logistics industry, lake tourism and leisure industry, art industry and other leading industries of lake economy. Intensify the core status of Hongta District while quickening the pace of eastward urban expansion. With the opportunity of transforming Jiangchuan County to Jiangchuan District, boost the transformation development of Jiangchuan, accelerate the development of county economy to urban economy, complete the adjustment and revision of the overall urban planning of Jiangchuan, and initiatively undertake the vocational education, scientific research, aircraft industry, exhibition, cultural tourism and other service functions in Hongta District. Establish the urban management mechanism of One Core and Two Hearts, change the management style, push forward new-type industrialization, urbanization and agricultural modernization with all strength, and speed up the development of tourism industry and eco-friendly industry. Build new Jiangchuan-Tonghai Expressway and South Beltway, get through the passageway from Jiuxi to Yanhe, transform and update the old Yuxi-Jiangchuan Expressway to Urban Expressway so that the Hongta District and Jiangchuan District are linked more closely, and promote the complementary and integrative development of the two districts to build a city with One Core and Two Hearts. Fully play the leading role of One Core and Two Hearts of Hongta District and Jiangchuan District, speed up to transform Tonghai County and Chengjiang County to Tonghai City and Chengjiang District, implement differentiated industrial policies, be coordinated and complementary with each other, highlight the characteristics, build Chengjiang to be an important node on the red tourism culture industry economy belt from Yuxi to Kunyang, build Tonghai to be national-level historical and cultural city, and E'shan to be a landscape garden city with the Yi nationality culture as the carrier in order to construct the core city group framework of Yuxi. (1) The selection strategy of industry type based on ecological safety. The industry selection for the three-lake ecological urban agglomeration area must be based on the premise that the lake ecosystem health is not damaged. Before selecting and introducing the industry types, we shall use the health evaluation system of the lake ecosystem to evaluate the current health of all regional water. Strictly forbid the introduction of industries, develop suitable industries that can be imported and create conditions for introducing industries. (2) The construction strategy of industrial cluster with creativity and innovation as cores and characteristics. Combined with the fossil resources in Maotian Mount, the bronze cultural resource in Lijiashan, the unique minority resources of Mongol and Yi minority and characteristic festival resources and with the three main strategy lines: health lakes, creative industries and urban and rural overall development, we put forward four industry concepts: culture creativity, environmental protection creativity, science and technology creativity and agriculture innovation, and build four industries based on above; develop the five leading industries with all strength: cultural creativity, pilot plant test of scientific research, lake tourism, environmental protection industry and the production of green aquatic products, and build the brand image of the three-lake ecological urban agglomeration. Meanwhile, we shall pay attention to the trend guidance for the industry system organization strategy with originality extension as a path. Strive to develop all districts, build a multi-level and circular economy system with regional linkage, park interaction and enterprise autonomy, and establish a resource recycling system for the whole society and a new pattern of industrial space agglomeration. (3) The land intensification strategy and social security strategy. Overall plan the core land and surrounding rural land of new cities and improve the integration system; renovate the rural land and cultivate and expand the economic growth points to form the interactive situation of "countryside supporting city and city back seeding countryside" ; unify the functions of urban and rural land, the value connotation of the land with same function shall be consistent and not be distinguished - collective 
or state-owned; build a unified urban-rural land market and confirm the property rights. With the direction of overall planning the urban and rural economic development and boosting the city and countryside integration, in order to practically protect the basic livelihood of land-expropriated farmers and promote employment, establish a social security system and operating mechanism matched with the economic and social development level for the land-expropriated farmers. Moreover, we shall actively support and encourage the land-lost farmers to find jobs or start up business.

The three plateau lakes are the characteristic recourses in Yuxi ecological urban circle. The urbanization development in the plateau lake drainage basin shall be different from that in other regions. We shall take the protection and development the lake ecological resources as the power and follow the principle of protection first, moderate exploitation and concentrated development to establish a complete system and early warning mechanism for the healthy lake ecosystem evaluation, cultivate the development pole of Yuxi ecological city, develop an industrial cluster with ecological priority and creativity as core, and take the urban-rural interaction as the safeguard measure for the regional linkage development, so as to realize the harmonious coexistence of urbanization development and the lake ecosystem.

\section{Acknowledgement}

Task: the planned project supported by Yunnan college irtstyn and the irtstyn for structural adjustment of agriculture and non-point source pollution treatment of plateau lake drainage basin of Yunnan colleges (IRTSTYN201422).

\section{References}

[1] Wu Xianhua, Investigation of the Ecotope and Resources Protection Management System of Fuxian Lake, Yuxi Daily, Special for Fuxian Lake, 2017-06-22.

[2] Cui Yanyao, Planning Study on the Urban Water Front Based on the Ecological Idea, Tongji University, 2007.

[3] Wang Jianguo, Lv Zhipeng, the History Course and Experience of Exploitation and Construction of Urban Water Front in the World, City Planning, 2001.

[4] People's Government of Yunnan Province: New-type Urbanization Planning in Yunnan Province (2014 - 2020).

[5] Yuxi Municipal People's Government: Outline of the 12th Five-Year Plan for National Economy and Social Development of Yuxi City (2014-2020). 